\title{
Proximal Peer-Level Effects of a Small-Group Selected Prevention on Aggression in Elementary School Children: An Investigation of the Peer Contagion Hypothesis
}

\author{
Paul Boxer, ${ }^{1,5}$ Nancy G. Guerra, ${ }^{2}$ L. Rowell Huesmann, ${ }^{3}$ and Julie Morales ${ }^{4}$
}

Received March 9, 2004; revision received August 15, 2004; accepted September 24, 2004

\begin{abstract}
Examined peer contagion in small group, selected prevention programming over one school year. Participants were boys and girls in grades 3 (46 groups, 285 students) and 6 (36 groups, 219 students) attending school in low-resource, inner city communities or moderate resource urban communities. Three-level hierarchical linear modeling (observations within individuals within groups) indicated that individual change in aggression over time related to the average aggression of others in the intervention group. The individual child was "pulled" toward peers' mean level of aggression; so the intervention appeared to reduce aggression for those high on aggression, and to make those low on aggression more aggressive. Effects appeared to be magnified in either direction when the child was more discrepant from his or her peers. From these results we derive a principle of "discrepancyproportional peer-influence" for small group intervention, and discuss the implications of this for aggregating aggressive children in small group programs.
\end{abstract}

KEY WORDS: aggression; elementary school; peer contagion; selected prevention; intervention.

Youth violence has been the focus of a national research agenda for many years (Human Capital Initiative, 1996; Murray, Guerra, \& Williams, 1997; Surgeon General, 2001), and research on the prevention of youth violence has been increasing steadily (Acosta, Albus, Reynolds, Spriggs, \& Weist, 2001). However, programs implemented to mitigate or prevent aggression and violence among children and adolescents typically show only modest to moderate effectiveness (Howard, Flora, \& Griffin, 1999; Wilson, Lipsey, \& Derzon, 2003), and a number of issues related to the optimal design of such programs remain unresolved (Boxer \& Dubow, 2002; Kerns \& Prinz, 2002). For example, in order to intervene with

\footnotetext{
${ }^{1}$ University of Michigan; currently at University of New Orleans.

${ }^{2}$ University of California, Riverside.

${ }^{3}$ University of Michigan.

${ }^{4}$ University of California, Riverside; currently at Division of Children, Youth, and Families of Jefferson County Human Services (Colorado).

${ }^{5}$ Address all correspondence to Paul Boxer, PhD, Department of Psychology, University of New Orleans, 2001 GP Building/Lakefront, New Orleans, LA 70148; e-mail: pboxer@uno.edu.
}

children most at-risk and to deliver services in a costeffective manner, many prevention programs recruit participants who are rated as aggressive and provide interventions for small groups of identified children. Those programs are referred to as selected or secondary prevention programs, and often can result in the creation of intervention groups comprised entirely of the most aggressive youth.

Selected prevention activities are designed to prevent the emergence of a full-scale disorder following the initial appearance of signs or symptoms of the problem (Gordon, 1983). With regard to aggressive behavior, this typically refers to preventing escalations from aversive and disruptive interpersonal behavior problems to serious violence and antisocial offending (Tolan \& Guerra, 1994). Given the mix of risk factors commonly associated with the development of aggressive behavior (for reviews, see, e.g., Coie \& Dodge, 1998; Dodge \& Pettit, 2003; Huesmann, 1994), including personal characteristics (e.g., IQ, temperamental predisposition; Huesmann, Eron, \& Yarmel, 1987; Miles \& Carey, 1997) as well as contextual influences (e.g., poverty, family violence; 
Guerra, Huesmann, Tolan, Van Acker, \& Eron, 1995; Mahoney, Donnelly, Boxer, \& Lewis, 2003), children identified for selected prevention activities might be contending with a variety of psychosocial difficulties. However, as the strongest predictor of later aggression and antisocial behavior is early and contemporaneous aggression (Borum, 2000; Dubow, Huesmann, \& Boxer, 2003; Huesmann, Eron, \& Dubow, 2002), children likely are best identified for selected activities through a detailed, multi-informant assessment of aggression and related behavior problems (Flanagan, Bierman, Kam, \& Conduct Problems Prevention Research Group, 2003).

\section{Selected Prevention for Aggression}

There are several ways in which selected prevention programming for aggression can be implemented. Given the utility of schools for delivering violence prevention services (Farrell, Meyer, Kung, \& Sullivan, 2001), one of the more common approaches is to employ classroom "pull-out" programs for students labeled as "at risk" or "high risk." In this approach, students are removed from their regular classrooms for a period of time (typically 30$60 \mathrm{~min}$ ) to receive prevention programming in a different room. Hudley and her colleagues and Lochman and his colleagues have used this strategy effectively in smallgroup interventions for anger and aggression among elementary and young middle school students (Hudley et al., 1998; Hudley \& Graham, 1993; Larson \& Lochman, 2002; Lochman \& Lenhart, 1993). Feindler and her colleagues have obtained success with similar programs for older students (Feindler, Marriott, \& Iwata, 1984; Feindler \& Scalley, 1998).

The selected approach has some clear benefits. For example, teachers and parents can see that youth in need of services are receiving them; through "pullout" programs teachers and classmates receive respite from particularly disruptive youth. Further, selected programming can be less of a strain on financial and human resources over the short-term when compared to broad-based universal or intensive indicated programming. Still, this approach has potential costs. Recent theory advanced by Dishion and colleagues (Dishion, Bullock, \& Granic, 2002; Dishion, McCord, \& Poulin, 1999) based upon a body of research into adolescent peer relations and the development of antisocial behavior (Patterson, DeBaryshe, \& Ramsey, 1989; Patterson, Dishion, \& Yoerger, 2000; Poulin, Dishion, \& Burraston, 2001; Poulin, Dishion, \& Haas, 1999; Reid, Patterson, \& Snyder, 2002) offers a contraindication to the selected prevention approach.

\section{Peer Contagion in Selected Prevention for Aggression}

The peer contagion hypothesis predicts that intermingling antisocial youth in the context of intervention activities encourages them to behave more antisocially. For example, those youth can reinforce each other for problem behavior during group sessions (e.g., one youth insults the group leader and the others laugh), expose one another to new antisocial ideas and experiences (e.g., one youth informs another of an easy burglary target), and form enduring relationships that could increase their exposure to one another's deviance over the long term. In other words, it is precisely the selected prevention strategy that might result in iatrogenic effects for an intervention program. By aggregating youth who display higher-thanaverage levels of aggressive, antisocial behavior, an intervention ostensibly intended to reduce or prevent such behavior might actually increase it.

Evidence for the peer contagion hypothesis has been documented in randomized intervention studies. Dishion et al. (1999) noted that short-term benefits had accrued from a cognitive-behavioral group intervention to reduce problem behavior among high-risk adolescents. However, results from a 3-year follow-up indicated that treated youth were more likely to self-report tobacco use, and were rated as more delinquent by teachers, than nontreated youth. Similar observations of the negative effects of aggressive peers have been found in recent longitudinal studies. For example, Espelage, Holt, and Henkel (2003) observed peer-group effects on individual aggressive behaviors in a sample of students in sixth through eighth grade. Students were grouped according to their naturally occurring peer group affiliations (i.e., groups of friends identified via social network analysis). Results revealed significant between group variation in individual aggression outcomes. Specifically, higher levels of aggregated fighting and bullying within peer groups at time 1 predicted increased fighting and bullying at time 2 for the individuals comprising those groups, after controlling individual aggression at time 1 .

Although there is a growing body of evidence supporting the peer contagion hypothesis, there are still many questions regarding the process by which this occurs. Otherwise put, it is important to disentangle characteristics of aggressive groups that are most predictive of impact on individual aggression. For instance, it may be that mere exposure to the aggression of peers in a group influences changes in individual aggression such that exposure to more aggressive peers leads to greater increases in aggression over time in a direct fashion. In contrast, it may be that children are differentially affected by group aggression depending upon their own individual levels of 
aggression at the outset of group formation such that exposure to more aggressive peers is more detrimental to the behavioral functioning of relatively less aggressive individuals.

Further, little is known about the role of age as a moderator of peer group influence. Indeed, most studies of peer influence on aggression have used adolescent samples. This is not surprising given the increasing importance during adolescence of the peer group in shaping a variety of individual outcomes including alcohol use (Curran, Stice, \& Chassin, 1997), school adjustment (Berndt \& Keefe, 1995), and emotional adjustment (Baker, Milich, \& Manolis, 1996), in addition to antisocial behavior. However, it also is important to examine whether peer contagion effects seem to be operating in younger samples. Clearly, from a very early age, children enter into peer relationships and friendships with others who display behaviors similar to their own (Epstein, 1989; Newcomb, Bukowski, \& Bagwell, 1999). A recent study by Goldstein, Arnold, Rosenberg, Stowe, and Ortiz (2001) indicated that peer contagion effects on aggression can be present in preschool-age children. Still, less is known about the influence of peer groups on children's developing aggressive behaviors at younger ages than in adolescence.

In addition, it is important to examine whether iatrogenic effects of peer groups vary by gender. Many previous studies have used samples comprised primarily of males. Where female samples have been included few results of gender effects have been reported (Dishion, 2000; Espelage et al., 2003; Granic \& Dishion, 2003; Poulin, Dishion, \& Burraston, 2001). Thus, less is known about the peer contagion hypothesis with female samples. Although males and females display similar degrees of short-term continuity in aggression during childhood (see Huesmann \& Moies, 1998), sex differences in susceptibility to peer influence might be present. For example, a recent report by Kiesner, Poulin, and Nicotra (2003) suggested that males and females differ in the extent to which in-school and after-school peer groups influence their antisocial behaviors.

Finally, the community context also might moderate peer contagion effects. Positive relations often are observed between neighborhood-level socioeconomic advantage and healthy or competent child outcomes, partially on account of the greater availability and quality of resources such as social and recreational activities (cf. Leventhal \& Brooks-Gunn, 2003). With respect to peer contagion, in communities with greater resources and more opportunities, specific peer groupings might be expected to exert a lesser influence on problem behavior. Children who spend their time in a variety of activities with a variety of peers (such as organized sports, recreation, and play groups) might be less susceptible to the influence of any one deviant or aggressive group. This would be particularly true for small group interventions, where groups meet briefly during the school day over a relatively brief period of time.

\section{The Current Study}

In this study, we examined peer contagion effects on aggression with data from the Metropolitan Area Child Study (MACS; Guerra, Eron, Huesmann, Tolan, \& Van Acker, 1997; MACS Research Group, 2002). The MACS was a large-scale developmental and prevention study conducted in the 1990s with elementary school children attending urban, moderate resource schools and inner-city, low resource schools. Schools were assigned randomly to one of four conditions: a no-treatment control condition; a classroom-only social-cognitive and teacher training intervention (Level A); the classroom program plus a small group intervention for high aggressive children (Level B); and the classroom plus small group plus family intervention for high aggressive children (Level C). Successive cohorts of children were studied for the 7 years from 1991 to 1997.

Our interest in examining processes and moderators of peer contagion effects in this sample comes from previously reported findings suggesting negative (iatrogenic) effects of the classroom plus small group (Level B) intervention (MACS Research Group, 2002). Specifically, older students (Grades 5-6) from both low resource and moderate resource schools who participated in this intervention decreased significantly less in aggression over time than did controls (MACS Research Group, 2002, p. 185). This iatrogenic effect for the Level B intervention was not significant for younger children (Grades 2-3) though the changes in their aggression suggested such an effect within the lower resource community. Moreover, for both younger and older youth in the lower resource community, the outcome of the small group plus family intervention (Level C) was in the iatrogenic direction even though the outcome of this intervention for the moderate resource community showed preventive effects on aggression (MACS Research Group, 2002, p. 187). Overall, these earlier analyses suggest that the small group intervention for both younger (Grades 2-3) and older (Grades 5-6) children from lower resource communities either has no effect or has a significant iatrogenic effect.

The purpose of the current study, then, is to explore characteristics of the small groups that might have accounted for those iatrogenic effects and the characteristics 
of individuals and settings that may moderate those effects. First, we are interested in whether there is variation in aggressive behavior unique to small groups themselves that is associated with individual increases or decreases in aggression over the course of the intervention. Second, we are interested in whether age, gender, and community resources moderate those effects. Our hypothesis is that the average level of initial aggression in the intervention group will predict the amount and direction of change in aggression for individuals in the group. In particular, we expect individuals to be "pulled" toward the average level of aggression of the other children in the group. We also expect that this "peer group contagion" effect might be more evident in older children than in younger children, and more evident in males than in females. In addition, we expect the peer group aggression level to be more strongly associated with change in individual aggression in lower resource communities than in moderate resource communities.

\section{METHODS}

\section{Participants}

\section{Group Characteristics and Selection}

Data were available from 207 intervention groups conducted during the 7 years of the Metropolitan Area Child Study (1991-1997). As described elsewhere (MACS Research Group, 2002), the interventions were conducted in the 2nd and 3rd grade and 5th and 6th grade on successive cohorts of children. The intervention of interest for this paper was a small group program (SGP) in which the target youth met together with the same set of four to ten youth and two staff facilitators once a week. More details on the intervention procedure are provided below. Of course, the child composition of each such group changed from year to year which precluded us from treating successive years as part of one intervention process. The children received a greater number of intervention sessions during the $3 \mathrm{rd}$ and 6 th grade than in the 2 nd or 5 th (i.e., 16 sessions in the 3rd and 6th grades compared to 12 in the 2 nd and 5 th grades); so we decided to focus on the analysis of the peer-group process in the 3rd and 6th grades for this study. Only a very few children participated in both the grade- 3 and grade- 6 intervention (i.e., 19 out of 285 relevant participants); so we analyze the two grades separately in this study. As an additional inclusion criterion for analyses, we selected only those groups for which data from at least four members were available (most groups met this criterion). The final sample for analysis included a total of 82 groups (mean number of participants $=6$ ); of those, $46(56 \%)$ had received grade-3 interventions whereas 36 (44\%) had received grade- 6 interventions. Across the $3 \mathrm{rd}$ and 6th-grade intervention periods, group composition by sex and ethnicity was comparable. By sex, groups averaged about $60 \%$ male participants $(62 \%$ 3rd grade; $58 \%$ 6th grade). By ethnicity, groups averaged about $37 \%$ African-American participants (34\% 3rd grade, $40 \%$ 6th grade), and $42 \%$ Hispanic participants (43\% 3rd grade, $41 \%$ 6th grade). About $60 \%$ of groups in the final sample were from schools in moderate resource communities and $40 \%$ from schools in lower resource communities.

As noted earlier, schools were randomly assigned to one of four intervention conditions (Control, A, B, or C). Two of those included the small group program: The Level B condition, which included a general enhancement classroom program along with the small group program; and the Level $\mathrm{C}$ condition, which included the Level B components plus a family group therapy component. Of the groups selected for analysis in this study, $61 \%$ came from the Level B condition and 39\% came from the Level C condition.

Within schools, small groups were constructed based on scheduling needs of classroom teachers. The small groups were administered as "pull-out" programs and thus it was essential to coordinate with teachers to ensure that children did not routinely miss any academic instruction. Although children often were drawn from multiple classrooms to create small groups, out of necessity sometimes a group was comprised entirely of children from one classroom.

\section{Individual Participants}

The 46 grade- 3 intervention groups contained 285 students (177 males, 108 females; 34\% African American, $24 \%$ Caucasian, $43 \%$ Hispanic). The 36 grade-6 intervention groups contained 219 students (127 males, 92 females; 40\% African American, 20\% Caucasian, 41\% Hispanic). As noted above, the grade- 3 and grade- 6 intervention samples were not completely independent. Nineteen students were included in both time periods, contributing data at the peer group level to eight groups in the early intervention and five groups in the late intervention. Those students were retained in order to maximize the number of peer groups available for analysis, and analyses were conducted separately by intervention period to accommodate this dependency. ${ }^{6}$

\footnotetext{
${ }^{6}$ An alternative would be to eliminate the overlapping 19 participants from our analyses and compute a single model with age as a
} 
The overall design has been described previously in extensive detail (Guerra et al., 1997; MACS Research Group, 2002). Briefly, it should be emphasized that the students included in the current study all were identified as high risk for engaging in aggression through combined teacher reports and peer nominations (measures described below). Thus, these students all were displaying more aggression than their peers in the studied schools at the start of the intervention.

Because the focus of this paper is on characteristics of small groups associated with behavior change, data from high-risk students assigned to the two conditions without a small group component (i.e., no-intervention control; classroom enhancement intervention only), are not examined. Similarly, low risk children are not studied because no low risk child received a small group intervention.

It also should be noted briefly that the MACS was implemented in two types of communities: urban, moderate-resource communities and inner-city, lowresource communities. Although the moderate-resource communities were marked by objective levels of socialeconomic distress (e.g., high poverty and unemployment), the lower-resource communities were relatively more distressed. Lower-resource communities had lower median family incomes, higher rates of poverty, higher unemployment, less owner-occupied housing, and higher crime-rates than moderate-resource communities (MACS Research Group, 2002).

\section{Measures}

\section{Composite Aggression Measure}

The measure of interest in the current study is a composite measure of students' aggressive behavioral tendencies, formed as the combination of teacher ratings on the Aggression subscale from the Teacher Report Form

\footnotetext{
between-groups predictor. However, because our principal interest was in the examination of effects at the level of the peer group, this approach was not tenable. Although eliminating those 19 children from analyses would have resulted in relatively minor reductions in the individuallevel sample $n$ values across intervention periods (i.e., 285 to 266 in the early period; 219 to 200 in the late period), reductions are more dramatic at the peer group level. Those 19 children were members of eight different groups in the early intervention period and five different groups in the late intervention period. The reduction in $n$ at the group level would have been far less acceptable (i.e., 46 to 38 groups in the early period; 36 to 31 groups in the late period). Given that the primary focus of our analysis was on the Level 3 effects accruing from those groups in our three-level hierarchical models, we elected to retain those individual participants and compute the analyses separately by intervention period.
}

(TRF) of the Child Behavior Checklist (Achenbach \& Edelbrock, 1983), and peer nominations on the Aggression subscale of the Peer Nomination Inventory (Eron, Walder, \& Lefkowitz, 1971). The TRF Aggression scale contains 30 items describing various aggressive acts (e.g., "fights," "yells") and rated as $0=$ "never true," $1=$ "somewhat or sometimes true," or 2 = "very or often true." Raw item scores were summed to provide a total score. The peer nomination form contains ten items describing various aggressive acts (e.g., "pushes and shoves other kids," "gets in trouble with the teacher"); children can nominate as many classmates as they choose as exemplars of the different behaviors. Scale scores provide a composite of the ratio indicating the number of times a child was nominated for each behavior with respect to the number of times a child could have been nominated (i.e., number of children in class). In some classrooms, however, peer nominations could not be obtained (approximately 23\% of assessments across the full time period of the MACS). In those cases, the peer nomination score was replaced by the Teacher's Predictions of Peer Nominations measure (Huesmann, Eron, Guerra, \& Crawshaw, 1994). This measure has been shown to provide highly reliable and valid estimates of actual peer nominations. Although the TRF and peer nomination scales yield adequate estimates of aggressive behavior on their own, the composite aggression score provides the greatest degree of both reliability and validity and thus a much better estimate of children's aggressive behavior (see MACS Research Group, 2002, or Spindler \& Huesmann, 1999, for computational details). Composite aggression scores range from 0 to 4.5 , with higher scores indicating higher levels of aggressive behavior.

TRF and peer nomination scores obtained during preintervention assessments were used separately to identify high-risk students for participation in the Level B and $\mathrm{C}$ conditions. Students were classified as high-risk using median units (i.e., individual score minus median divided by median) computed from the two scores. Median units from the peer and teacher ratings were averaged. Highrisk students had median unit scores that were .5 or higher units above the full sample median, or between -.5 and .5 of the full sample median and .5 or higher units above the median for their own school and grade (MACS Research Group, 2002).

In addition to pre- and post-test individual composite aggression scores, we created two aggregate composite aggression scores to assess overall aggressiveness of the peer group. First, for each participant, we computed the mean pre-test aggression score of all other small-group peers (cf. Henry et al., 2000). This score is unique to the individual and reflects a child's degree of exposure to peer aggression within his or her small group (i.e., the 
individual's aggression score is not included in this mean). Second, for each group, we computed the mean pre-test aggression score of all members of the small group.

\section{Procedures}

\section{Small Group Program}

The small group program (SGP) was designed to serve primarily as a supplement and enhancement to the classroom enhancement program (CEP). The CEP was a curriculum entitled "Yes I Can" that relied on a general social-cognitive and social learning orientation to target five component areas: 1) self-understanding (e.g., improving emotion recognition and labeling), 2) self in relation to others (e.g., understanding different social groups and bonding), 3) moral beliefs (e.g., modifying normative beliefs about the appropriateness of aggression), 4) sense of control (e.g., training prosocial control strategies), and 5) social problem-solving (e.g., increasing the use of prosocial, non-aggressive behavioral scripts). The SGP was presented to the high-risk students as a "leadership training program," and they were challenged to participate in order to assist with teaching their low-risk peers the content included in the whole-classroom programming.

The SGP provided a more intimate and focused venue for high-risk youth to receive additional instruction on, and practice the skills they learned in the CEP. Further, the SGP was designed to focus more intently on six areas of peer relations identified as most problematic for the target population: initial social interaction, solving social conflicts, understanding ambiguous behavior and situations, handling victimization, and forming friendships (Asher, Rose, Guerra, \& Tolan, 1993). Children attended group sessions for one hour per week over 28 weeks during the course of 2 years (Guerra et al., 1997). Complete detail on the small-group curriculum can be found in Eargle, Guerra, \& Tolan (1994).

All SGP groups were led by trained facilitators, who were required to hold at least a bachelor's degree in the behavioral sciences and were recruited from the community and the university (University of Illinois-Chicago). Trained undergraduates served as co-leaders. Thus, all groups were led by two facilitators, and the facilitatorstudent ratio rarely exceeded about 1:5. All group leaders received two 6-hour initial training sessions, and weekly group and individual supervision conducted by advanced clinical psychology graduate students for the duration of the intervention period. The supervising clinical students met regularly with the supervising project investigator. Initial training and ongoing supervision of facilitators in- cluded a focus on the mastery and implementation of behavior management techniques. In practice, techniques centered mainly on the application of individual rewards (e.g., tickets that could be exchanged for small prizes) and group contingencies (e.g., group snacks for appropriate behavior). Treatment fidelity analyses indicated that approximately $90 \%$ of planned activities were implemented in the SGP (Eargle et al., 1994; MACS Research Group, 2002).

\section{Assessment Procedures}

Pre-test assessments were conducted during the spring of the year prior to the first intervention year. Posttest assessments were conducted at the close of the second intervention year. Peer nominations and TRF reports were collected at both pre- and post-test. For first graders, peer nominations were collected via individual interviews; for children beyond first grade, peer nominations were collected during classroom-wide assessment periods. Teachers completed their TRFs individually.

\section{RESULTS}

\section{Initial Data Processing}

Because of both individual and school attrition, missing data are a serious problem in the Metropolitan Area Child Study particularly when one desires to evaluate aspects of the interventions. Our solution to this problem has been to use multiple imputation (Little \& Rubin, 1987) to estimate much of the missing data. The procedures used have been described in more detail elsewhere (MACS Research Group, 2002), but essentially involve estimating five versions of the data with state-of-the-art algorithms and some restrictions on requiring minimal data on each child. In particular, we only impute missing values when we have data on the child collected during the same wave or in both a prior and successor wave. The resulting five data sets can generally be averaged to obtain unbiased estimates of most population parameters, but computing appropriate standard errors for significance tests requires other techniques. In the current case, we employ Hierarchical Linear Modeling (HLM; Raudenbush \& Bryk, 2002) for all analyses, which simplifies the problem for two reasons. First, HLM is very robust for missing data; so the remaining smaller amount of missing values in our data is not a serious problem. Second, the HLM 5 program accepts the five multiply imputed data sets as input and automatically constructs corrected standard errors for the parameter estimates it derives. 
Table I. The Hierarchical Linear Model for Predicting Changes in Aggression in Peer-Intervention Groups

\begin{tabular}{|c|c|}
\hline \multicolumn{2}{|l|}{ Level 1: For each time } \\
\hline 1.0) & Aggression $=\pi 0+\pi 1 \times$ Time $+\mathrm{R}$ \\
\hline \multicolumn{2}{|l|}{ Level 2: For each person } \\
\hline 2.0) & $\pi 0=\beta 00+\beta 01 \times$ Ave pretest agg of peers $+\beta 02 \times$ Gender $+\mathrm{U} 0$ \\
\hline 2.1) & $\pi 1=\beta 10+\beta 11 \times$ Ave pretest agg of peers $+\beta 12 \times$ Gender $+\mathrm{U} 1$ \\
\hline \multicolumn{2}{|c|}{ Level 3: For each peer group } \\
\hline 3.00$)$ & $\begin{array}{l}\beta 00=\gamma 000+\gamma 001 \times \text { Community resources }+\gamma 002 \times \text { Ave pretest agg of group } \\
\quad+\gamma 003 \times(\text { Community resources } \times \text { Ave pretest agg of group })+\text { U00 }\end{array}$ \\
\hline 3.01$)$ & $\begin{array}{l}\beta 01=\gamma 010+\gamma 011 \times \text { Community resources }+\gamma 012 \times \text { Ave pretest agg of group } \\
\quad+\gamma 013 \times(\text { Community resources } \times \text { Ave pretest agg of group })+\text { U01 }\end{array}$ \\
\hline 3.02$)$ & $\begin{array}{l}\beta 02=\gamma 020+\gamma 021 \times \text { Community resources }+\gamma 022 \times \text { Ave pretest agg of group } \\
\quad+\gamma 023 \times(\text { Community resources } \times \text { Ave pretest agg of group })+\mathrm{U} 02\end{array}$ \\
\hline 3.10$)$ & $\begin{array}{l}\beta 10=\gamma 100+\gamma 101 \times \text { Community resources }+\gamma 102 \times \text { Ave pretest agg of group } \\
\quad+\gamma 103 \times(\text { Community resources } \times \text { Ave pretest agg of group })+U 10\end{array}$ \\
\hline 3.11$)$ & $\begin{array}{l}\beta 11=\gamma 110+\gamma 111 \times \text { Community resources }+\gamma 112 \times \text { Ave pretest agg of group } \\
\quad+\gamma 113 \times(\text { Community resources } \times \text { Ave pretest agg of group })+\text { U11 }\end{array}$ \\
\hline 3.12) & $\begin{array}{l}\beta 12=\gamma 120+\gamma 121 \times \text { Community resources }+\gamma 122 \times \text { Ave pretest agg of group } \\
\quad+\gamma 123 \times(\text { Community resources } \times \text { Ave pretest agg of group })+\mathrm{U} 12\end{array}$ \\
\hline \multicolumn{2}{|r|}{ r } \\
\hline Aggression & $\begin{array}{l}\text { Target's composite score of peer nominations of aggression and teacher's report on } \\
\text { CBCL-aggression }\end{array}$ \\
\hline Time & $-1=$ pre intervention assessment $0=$ post intervention assessment \\
\hline Ave pretest agg of peers & $\begin{array}{l}\text { The average pre intervention composite aggression score for the other children in } \\
\text { target's peer intervention group }\end{array}$ \\
\hline Ave pretest agg of group & $\begin{array}{l}\text { The average pre intervention composite aggression score for all childrenin target's } \\
\text { peer intervention group including } \mathrm{S}\end{array}$ \\
\hline Community resources & The resource level of target's community. Coded 1 for moderate, 0 for low \\
\hline \multicolumn{2}{|l|}{ Interpretations } \\
\hline$\pi 0$ & The post-test aggression score for target child $i$ \\
\hline$\pi 1$ & $\begin{array}{l}\text { The rate of change in aggression from pre-test to post-test for target child } i \text {. A } \\
\text { negative value indicates a decline from pre-test to post-test. A positive value } \\
\text { indicates an increase. }\end{array}$ \\
\hline
\end{tabular}

\section{Analysis Models}

We applied three-level HLM to test our hypotheses about peer contagion effects on aggression using the HLM 5 program (Raudenbush, Bryk, Cheong, \& Congdon, 2000). This allowed us to represent appropriately the change in aggression during the intervention of children who are nested within different peer-intervention groups. The model predicts the composite aggression score for any child as a linear function of time (pretest $\rightarrow$ posttest; Level 1 of the model), characteristics of the child (Level 2 of the model), characteristics of the peer-group in which the child received the small-group intervention (Level 3), and the characteristics of the community in which the small-group was located (Level 3). The model is specified by the series of equations shown in Table I.

As seen in Table I, at Level 1 the model indicates that the child's composite aggression is a linear function of time plus random error. Time is the unit of observation for Level 1. There are two times being modeledpre-intervention assessment time (coded -1) and post- intervention assessment time (coded 0). At Level 2 the model indicates that a child's slope and intercept for the Level 1 model are related linearly to the average aggression level of the other children in the child's peerintervention group (Ave Pretest Agg of Peers), the child's gender, and random error. As noted above, the Ave Pretest Aggression of Peers is unique to the individual child and indicates a child's degree of exposure to peer aggression in other members of his or her intervention group. Children are the unit of observation for Level 2; so there are 285 observations at Level 2 in the grade-3 intervention and 219 in the grade- 6 intervention. At Level 3 the model specifies that the slopes and intercept of the Level 2 model are each also related linearly to two characteristics of the small group and their interaction: the average aggression in the entire intervention group (Ave Pretest Agg of Group) and the amount of resources in the community (Community Resources). Intervention groups are the unit of observation at Level 3; so there are 46 observations at Level 3 in the grade- 3 intervention and 36 in the grade- 6 intervention. In computing the Average Pretest Aggression of 
Table II. Parameter Values Estimated for the Hierarchical Linear Model Predicting Change in Aggression from Peer Contagion and Community Resource Factors in the Grade-3 Intervention

\begin{tabular}{lccc}
\hline \multicolumn{1}{c}{ Variable } & $\begin{array}{c}\text { Effect on pre-test/post-test } \\
\text { slope for aggression }\end{array}$ & Standard error & $t$-value \\
\hline Ave pretest agg of peers $(\beta 11)$ & .823 & .396 & $2.078^{*}$ \\
Ave pretest agg of group $(\beta 10: \gamma 102)$ & -.997 & .330 & $-3.026^{* *}$ \\
Community resources $(\beta 10: \gamma 101)$ & -.355 & .137 & $-2.596^{*}$ \\
Ave pretest agg of group $\times$ & .882 & .385 & $2.288^{*}$ \\
$\quad$ Community resources $(\beta 10: \gamma 103)$ & & & \\
${ }^{*} p<.05 .{ }^{* *} p<.01$.
\end{tabular}

Peers at level 2 and the Average Pretest Aggression of the Group at level 3, we used the averages of the five imputed values for all the relevant members of the group as the best estimate of the group characteristic.

The contributions of the Level 2 and Level 3 variables to the Level 1 slope of aggression on time (the slope $\pi 1$ in Table I) are of greatest interest in this paper. A significant negative contribution to the slope means that higher scores on the variable predict decreases in aggression from pretest to postest whereas a significant positive contribution indicates that higher scores predict increases in aggression from pretest to posttest.

It is important to clarify that although each level of the model includes information from each individual's aggression score at pre-test, this does not pose a problem with multicollinearity as would be the case in multiple regression. In our three-level HLM, the aggression variables at each level of the model represent characteristics at different, nested levels of observation: time, within individuals; individuals, within peer groups; and peer groups. To some extent, it was interest in exactly this type of analysis that led to the development of the HLM approach. In Bryk and Raudenbush's initial work on HLM (cf. Bryk \& Raudenbush, 1987, 1992; Raudenbush \& Bryk, 2002), examples can be found of models examining achievement over time, within individuals, within schools to examine school-level predictors of individual academic improvement. No known precedents exist for this type of analysis applied to aggression and peer contagion within intervention groups; however, the study by Espelage, Holt, and Henkel (2003) reviewed above represents a two-level variant of our approach to this issue. ${ }^{7}$

\footnotetext{
${ }^{7}$ In fact, the analytic model presented by Espelage et al. (2003) is quite similar to ours. Espelage and her colleagues demonstrated that levels of bullying and fighting in self-selected peer groups (Level 2 predictors of two-level HLM) were predictive of individual bullying and fighting outcomes (outcome variables) after controlling for initial levels of individual bullying and fighting (Level 1 predictors). Where our analyses differ is that our outcome variable is subsumed by Espelage et al.'s
}

\section{Results for Grade-3 Intervention Period}

Our initial HLM analyses with this model revealed that gender made no significant contribution to the Level 1 slope or intercept parameters; so gender was dropped from the Level 2 model (deleted from equations 2.0 and 2.1 in Table I), and the Level 3 equations predicting gender's effect were deleted (equations 3.02 and 3.12 in Table I). We found that the two Level 3 variables (Community Resources and Ave Pretest Agg of the Small Group) made no significant contributions to the Level 2 slope parameters for Average Pretest Aggression of the Peers; so equations relating them to those parameters were deleted (equations 3.01 and 3.11 in Table I).

The revised model without these terms was then estimated using the multiply imputed data from the grade- 3 intervention. The values derived for each parameter are shown in Table II along with their significance levels. All four of the variables whose parameters were estimated had significant effects on the slope relating time to aggression, i.e., on the change in aggression from pre-test to post-test. The .823 value for Ave Pretest Agg of Peers suggests that having more aggressive peers in the intervention group contributes to an increase in aggression for a target child. However, it can be misleading to interpret any one of these parameters in isolation, particularly with the interaction between community and Ave Pretest Agg of Group in the model. A better understanding can be obtained by calculating values for the slope of change in aggression under various conditions from the final model. This is done in Table III.

For the slope values shown in Table III, a negative value means that aggression from pretest to posttest is declining, and a positive value means it is increasing. One can see that in the moderate resource community, the aggressiveness of the other children in the intervention

outcome variable and Level 1 predictor, enabling us to specify other effects at Level 2 and consider the peer group at Level 3. 
Table III. Estimated Slopes ( $\pi$ 1) of Aggression on Time as a Function of Resources in the Community, Intervention Group Mean Aggression Level, and Participant's Peers' Mean Aggression Within their Intervention Group, Grade-3 Intervention

\begin{tabular}{lccc}
\hline & \multicolumn{3}{c}{ Group mean aggression } \\
\cline { 2 - 4 } \multicolumn{1}{c}{ Peers' mean aggression } & Above average & Average & Below average \\
\hline Lower-resource community & & & \\
$\quad$ Above average & .012 & 1.009 & 2.006 \\
Average & -.811 & .186 & 1.183 \\
$\quad$ Below average & -1.634 & -.637 & .360 \\
Moderate-resource community & .539 & .654 & .769 \\
$\quad$ Above average & -.284 & -.169 & -.054 \\
Average & -1.107 & -.992 & -.877 \\
Below average & & \\
\hline
\end{tabular}

Note. Aggression levels are: Below average $=$ one $S D$ below mean; Average $=$ mean; Above average $=$ one $S D$ above mean.

group (Peers' Mean Agg) has a fairly uniform and direct relation to the change in aggression that the target child experienced. The more aggressive were the peers, then the lesser was the decrease - or the greater was the increasein aggression of the target child during the intervention. Conversely, however, the more aggressive was the entire group (Group Mean Aggression), the greater was the decrease (or the less the increase) in aggression during the intervention.

To understand the meaning of these effects in combination, it is necessary to realize that the difference between the value of Group Mean Aggression and the value of Peer's Mean Aggression for any target child can only be the target child's own aggression. For example, the cells in the table below the diagonals represent where Peers' Mean Aggression is lower than the Group Mean Aggression. These cells represent the situation when the target child is more aggressive than his/her peers. These cells have the largest negative slopes from pre-test to posttest (lower resource community: $-.811,-1.634,-.637$; moderate resource: $-1.107,-.284,-.992)$. The less aggressive peers seem to be "pulling down" the aggressiveness of the target child. On the other hand, the cells in the table above the diagonal represent when Peers' Mean Aggression is higher than Group Mean Aggression. These cells represent the situation when the target child is less aggressive than his/her peers. In these cases, the slopes of change during the intervention are much more positive by comparison (lower resource community: 1.009, 2.006, 1.183; moderate resource: $.654, .769,-.054)$ indicating an increase (or very close to zero decrease) in aggression after the intervention. Interestingly, the pattern of magnitude of changes both above the diagonal and below the diagonal suggests that the strength of the peers' "pull" is proportionate to the discrepancy between the target child's and the peers' aggression. The "pull" is greatest in the corners where the discrepancy is greatest. For groups in the low resource community, the results show this pattern but with the negative effect of Group's Mean Aggression exacerbated. In other words, the pull of the peers' aggression on the target child's aggression is greater in the lower resource community.

Taken together, these results suggest a principle for understanding change in peer group interventions: the greater the discrepancy between the target child and the peers on the target behavior, the greater the movement of the target child toward the peers on that behavior. We propose this as a principle of "discrepancy-proportional peer influence." It implies that the more discrepant a target child is from his or her peers on a behavior, the more influence on changing that behavior the peers will have. To some extent, as indicated by the overall variability in aggression slopes shown in Table III, discrepancy-proportional peer influence should occur independently of-indeed, in some conditions, despite - any intervention effects. Further, the effect seems to be greater in lower resource communities.

\section{Results for Grade-6 Intervention Period}

We next analyzed changes in aggression for the children who received the intervention during grade 6 with the same HLM model. As in grade-3, child gender had no effect in initial analyses. Also as in grade 3, we found in our final model that Ave Pretest Agg of Peers was a significant predictor of the slope for change in aggression during the intervention (effect on slope $=2.233, S E$ $=.576, p<.01$ ), replicating the results for the grade- 3 intervention. As with the grade-3 intervention, the more aggressive were a target child's peers in the grade- 6 intervention group, the less therapeutic effect the intervention seems to have on a target child's aggression. However, 
Table IV. Parameter Values Estimated for the Hierarchical Linear Model Predicting Change in Aggression from Peer Contagion and Community Resource Factors in the Grade-6 Intervention

\begin{tabular}{lccc}
\hline \multicolumn{1}{c}{ Variable } & $\begin{array}{c}\text { Effect on pre-test/post-test } \\
\text { slope for aggression }\end{array}$ & Standard error & $t$-value \\
\hline Average pretest aggression of peers $(\beta 11)$ & 2.226 & .576 & $3.864^{*}$ \\
Average pretest aggression of group $(\beta 10: \gamma 102)$ & -.202 & .181 & -1.115 \\
Community resources $(\beta 10: \gamma 101)$ & -.145 & .181 & -.799 \\
\hline$* p<01$ & &
\end{tabular}

for the grade-6 intervention children, we did not find any significant effect of the Group's Mean Aggression independently of the peer's aggression. We also did not find significant effects of community resource level. The results of this HLM are shown in Table IV. Note, of course, that only the coefficient for our Level 2 Peer Mean Aggression variable is statistically significant; however the coeffiecients observed for the Level 3 predictors are in the same direction as those shown for grade 3 in Table II. Table $\mathrm{V}$ shows the estimates based on this model of individual changes over time in aggression. As with the grade3 estimates (Table III), the discrepancy-proportional peer influence ordinal pattern is evident even though the interaction was not significant. It can be seen that when an individual's aggression is lower than peers' aggression (coefficients above diagonals), the tendency is to increase in aggression over time; when an individual's aggression is higher than peers' (below diagonals), the tendency is to decrease in aggression over time.

\section{DISCUSSION}

We investigated peer contagion effects on aggression using data from the Metropolitan Area Child Study (MACS Research Group, 2002). An earlier report on the
MACS showed that treatment conditions that included small-group prevention programming but no family intervention led to increases in aggression relative to no intervention. The goal of this study was to examine possible peer group influences on changes in aggression within those intervention conditions. In addition, we examined individual and community factors that might moderate peer-group level effects.

Using three-level hierarchical linear modeling (HLM), we found evidence for peer influences on change in individual aggression from pre-intervention to postintervention in both younger (grade- 3 intervention) and older (grade-6 intervention) elementary school students. HLM analyses revealed peer influences on change in aggression at the level of the individual (i.e., children's unique level of exposure to peer aggression in their group). Specifically, exposure to higher levels of peer aggression at the individual level was associated with increases over time in aggression in the grade- 3 and grade- 6 intervention periods. Further, differences between total aggression in the group and the aggressiveness of a target child's peers also related to change in individual aggression.

Findings from the grade- 3 intervention led us to propose the principle of "discrepancy-proportional peer influence"-essentially, the more discrepant is a target child's behavior from that of his or her peers, the

Table V. Estimated Slopes $(\pi 1)$ of Aggression on Time as a Function of Resources in the Community, Intervention Group Mean Aggression Level, and Participant's Peers' Mean Aggression Within Their Intervention Group, Grade-6 Intervention

\begin{tabular}{lccc}
\hline & \multicolumn{3}{c}{ Group mean aggression } \\
\cline { 2 - 4 } Peers' mean aggression & Above average & Average & Below average \\
\hline Lower-resource community & & & \\
$\quad$ Above average & 2.022 & 2.224 & 2.426 \\
Average & -.204 & -.002 & .199 \\
$\quad$ Below average & -2.430 & -2.226 & -2.027 \\
Moderate-resource community & & & \\
Above average & 1.877 & 2.079 & .281 \\
Average & -.349 & -.147 & .054 \\
Below average & -2.575 & -2.371 & -2.172 \\
\hline
\end{tabular}

Note. Aggression levels are: Below average $=$ one $S D$ below mean; Average = mean; Above average $=$ one $S D$ above mean. 
more that child's behavior will change in the direction of the peer group's average. Our specified predictors at the peer-group level (Level 3) did not account for changes in aggression over time for children in the grade6 intervention. However, the pattern of results obtained from the grade- 6 intervention supported the principle of discrepancy-proportional peer influence. Peer contagion effects on change in aggression over time were not moderated by child sex in either grade level. The results of this investigation suggest important directions and considerations for theory relating to peer contagion, as well as future research and practice on selected prevention of youth aggression.

\section{Peer Contagion Effects}

Following Henry et al. (2000), we examined whether individual changes in aggression could be predicted by an index of the level of aggression to which they were exposed in their peer group-that is, the average level of aggression of their fellow group members. This provides one test of the peer contagion hypothesis in a way that is akin to studies exploring generally the influence of children's exposure to aggression in others on their own aggressive behavior (e.g., Boxer, Edwards-Leeper, Goldstein, Musher-Eizenman, \& Dubow, 2003; Guerra, Huesmann, \& Spindler, 2003). We found that for both younger and older children, higher levels of peer aggression were associated with increases in individual aggression over time. In one sense, this affords a direct inference of peer contagion that is quite consistent with social learning and social-cognitive models of aggressive behavior (Eron, 1987; Huesmann, 1998). That is, children are influenced by what they observe: greater observation of aggression is related to increases in children's own aggressive behavior over time (Anderson \& Huesmann, 2003; Crick \& Dodge, 1994; Eron, 1994; Huesmann, 1988, 1998). However, when considered with our findings at the level of the peer group, a more nuanced effect is suggested: namely, that children are motivated to reduce perceived discrepancies between their own and their peers' behaviors.

We found that changes in aggression over time appeared to be greatest when the individual target child was most discrepant from his or her peer group on levels of aggressive behavior. That is, highly aggressive children in less aggressive groups were likely to reduce their aggression over time in the context of intervention. Conversely, less aggressive children in highly aggressive groups were likely to increase their aggression over time, in spite of intervention. We term this effect as the principle of "discrepancy-proportional peer influence."
Unlike what is implied by general peer contagion effects on aggression (i.e., that aggressive peers should uniformly influence one another to behave more aggressively), the discrepancy-proportional peer influence principle suggests that aggressive peers can support reductions in aggression as well. Bringing a highly aggressive elementary-aged child into a relatively less aggressive group of peers in selected prevention should lead to reductions in that child's aggressive behavior. This proposition is consistent with earlier studies (e.g., Stoolmiller, Eddy, $\&$ Reid, 2000) showing that the most aggressive children appear to benefit the most from universal preventive intervention, in which most other children would be expected to show relatively lower levels of aggression.

The approach we used in this study is similar to the approach implemented by Espelage et al. (2003). Using two-level HLM, Espelage et al. (2003) found that aggression in children's chosen peer networks was positively related to children's individual aggression over time. The pattern of findings observed in their investigation, however, was only partially similar to our results. Specifically, Espelage et al. (2003) found that individual aggression was linearly and positively related to peer network aggression over time, with little variation accruing from individual-peer group discrepancies. The contrast is likely due to the critical difference that in the MACS, children did not choose their fellow peer group members. Future studies comparing the long-term outcomes of children involved in compulsory (e.g., intervention groups; detention centers) or voluntary (e.g., gangs; close friendships) associations with aggressive peers will aid in understanding any resulting contagion effects.

\section{Gender and Community Resource Issues}

No evidence was found to support gender as a moderator of peer effects on individual aggression in the current study. The lack of expected results associated with child gender may be due to the broad level at which we modeled aggression. The effects of gender might only be evident within specific subdomains of aggression (e.g., indirect aggressive behaviors; Björkqvist, 1994) that may require more elaborated measures to observe. In addition, the small group program was not tailored differently specifically for males and females. It is possible that addressing gender issues within programming would provide evidence of gender effects at the level of the peer group. Alternatively, as has been found in recent peer contagion research including females (Poulin et al., 2001) gender may simply not moderate peer contagion effects. However, given that some evidence for gender effects in 
deviancy training among peers has been observed, this issue merits further attention (Dishion, 2000; Granic \& Dishion, 2003).

The discrepancy-proportional peer influence principle appeared to be affected by community resource level. Following earlier work on the MACS (MACS Research Group, 2002), and considerable empirical research demonstrating the relation between socioeconomic disadvantage and children's aggression (Eron, Guerra, \& Huesmann, 1997), we had expected that group-level effects would be more prominent in the lower-resource communities. This was indeed our observation. Whereas the effects accrued in both communities, discrepancyproportional peer influence was greater in the lower resource community.

A final issue to consider relates to whether this investigation can shed light on earlier findings from the MACS demonstrating iatrogenic or null effects for children in the lower-resource communities who participated in smallgroup interventions (MACS Research Group, 2002). Our findings here suggest symmetric effects with respect to peer influence: peer-group processes appear to shape both increases and decreases in aggression, depending upon the individual-peer group discrepancy. These results taken together with the earlier report on the MACS indicate that peer-level processes related to aggression likely are only part of the explanation for the lack of effect or iatrogenic effect of the intervention in the lower resource communities. Peer contagion of aggression would represent only one aspect of the broader individualecological view on aggressive behavior development (Guerra \& Huesmann, 2004; Tolan, Guerra, \& Kendall, 1995), which posits that a variety of both personal and environmental factors interact to promote habitual aggression. It is important to note that in the lower resource communities, the presence of other risk factors for aggression (e.g., neighborhood violence and poverty; Guerra et al., 1995, 2003) might have mitigated any potential beneficial impact of peer process (i.e, for highly aggressive children in relatively less aggressive groups).

\section{Future Directions}

As has been noted often (e.g., Dishion et al., 1999; Dodge, 1999), researchers and practitioners engaged in interventions for aggression targeting youth in this age group and beyond (i.e., late childhood through adolescence) should take care in crafting those interventions as well as in evaluating and interpreting outcomes. As discussed earlier, the selected prevention approach to modifying children's aggression generally is well-established (e.g., Hudley et al., 1998; Larson \& Lochman, 2002), particularly among children in the late childhood through early adolescent age range. Results from this investigation do not indicate that the selected prevention approach should be abandoned entirely. In fact, over the short term it does seem as though a selected prevention program might work to bring very highly aggressive children's aggression down to more normative levels. However, this appears to be the case only under certain circumstances: among early elementary school children, when the highly aggressive child's behavior is quite discrepant from that of his or her peers.

The principle of discrepancy-proportional peer influence that we observed offers an augmentation of the general peer contagion model that should be explored in subsequent research and practice. Because the selected approach to preventive interventions for aggression is so common and can maximize available resources (e.g., few counselors available for many students), it certainly is worth exploring whether highly aggressive children in early elementary grades will reduce their aggression in selected peer groups comprised of relatively less aggressive peers. Of course, a similar approach has been tried in which aggressive children are joined with prosocial or non-aggressive peers, with generally positive outcomes (Conduct Problems Prevention Research Group, 1999; Hektner, August, \& Realmuto, 2003). However, it is questionable whether parents of nonaggressive children would routinely permit their children to be included in such activities, and a critical mass of aggressive children might "pull" non-aggressive peers in the direction of more aggression. Thus, discrepancyproportional peer influence would allow practitioners to employ a cost-effective mode of intervention for aggression among children in need of services without increasing the likelihood of placing other children at risk. Finally, it is important to note that when implementing any form of group intervention for aggressive children, the skill and experience of the group leaders or facilitators must be taken into account. Although group leaders in the MACS were trained and supervised extensively, the question must be raised whether more experienced leaders (i.e., licensed professionals) might have had success in curtailing or controlling negative peer group processes, thus mitigating contagion effects. Future studies might weigh the differential effects of peer contagion accruing in trainee- versus professional-led intervention groups.

\section{ACKNOWLEDGMENTS}

The Metropolitan Area Child Study has been supported with funding from the National Institute of Mental 
Health and the Centers for Disease Control and Prevention. Mateos Yosef (University of Michigan) assisted with the statistical analyses.

\section{REFERENCES}

Achenbach, T. M., \& Edelbrock, C. S. (1983). Manual for the child behavior checklist. Burlington: Department of Psychiatry, University of Vermont.

Acosta, O. M., Albus, K. E., Reynolds, M. W., Spriggs, D., \& Weist, M. D. (2001). Assessing the status of research on violence related problems among youth. Journal of Clinical Child and Adolescent Psychology, 30, 152-160.

Anderson, C. A., \& Huesmann, L. R. (2003). Human aggression. In M. A. Hogg \& J. Cooper (Eds.), Sage handbook of social psychology. London: Sage Publications.

Asher, S., Rose, A., Guerra, N. G., \& Tolan, P. H. (1993). Social tasks of inner city children. Unpublished manuscript, University of IllinoisChicago.

Baker, M., Milich, R., \& Manolis, M. (1996). Peer interactions of dysphoric adolescents. Journal of Abnormal Child Psychology, 24, $241-255$

Berndt, T. J., \& Keefe, K. (1995). Friends' influence on adolescents' adjustment to school. Child Development, 66, 1312-1329.

Björkqvist, K. (1994). Sex differences in physical, verbal, and indirect aggression: A review of recent research. Sex Roles, 30, 177-184.

Borum, R. (2000). Assessing violence risk among youth. Journal of Clinical Psychology, 56, 1263-1288.

Boxer, P., \& Dubow, E. F. (2002). A social-cognitive informationprocessing model for school-based aggression reduction and prevention programs: Issues for research and practice. Applied and Preventive Psychology, 10, 177-192.

Boxer, P., Edwards-Leeper, L., Goldstein, S. E., Musher-Eizenman, D., \& Dubow, E. F. (2003). Exposure to "low level" aggression in school: Associations with aggression, future expectations, and perceived safety. Violence and Victims, 18, 691-705.

Bryk, A. S., \& Raudenbush, S. W. (1987). Application of hierarchical linear models to assessing change. Psychological Bulletin, 101, $147-158$.

Bryk, A. S., \& Raudenbush, S. W. (1992). Hierarchical linear models: Applications and data analysis methods. Newbury Park, CA: Sage.

Coie, J. D., \& Dodge, K. A. (1998). Aggression and antisocial behavior. In W. Damon (Series Ed.) \& N. Eisenberg (Vol. Ed.), Handbook on child psychology: Vol. 3 Social, emotional, and personality development (5th ed., pp. 779-862). New York: John Wiley \& Sons.

Conduct Problems Prevention Research Group. (1999). Initial impact of the fast track prevention trial for conduct problems: I. The highrisk sample. Journal of Consulting and Clinical Psychology, 67, 631-647.

Crick, N. R., \& Dodge, K. A. (1994). A review and reformulation of social information-processing mechanisms in children's social adjustment. Psychological Bulletin, 115, 74-101.

Curran, P., Stice, E., \& Chassin, I. (1997). The relation between adolescent alcohol use and peer alcohol use: A longitudinal random coefficients model. Journal of Consulting and Clinical Psychology, $65,130-140$.

Dishion, T. J. (2000). Cross-cutting consistency in early adolescent psychopathology: Deviant friendships and problem behavior sequelae. Journal of Personality, 68, 1109-1126.

Dishion, T. J., Bullock, B. M., \& Granic, I. (2002). Pragmatism in modeling peer influence: Dynamics, outcomes, and change processes. Development and Psychopathology, 14, 969-981.

Dishion, T. J., McCord, J., \& Poulin, F. (1999). When interventions harm: Peer groups and problem behavior. American Psychologist, $54,755-764$
Dodge, K. A. (1999). Cost-effectiveness of psychotherapy for child aggression: First, is there cost effectiveness? Comment on Schectman and Ben-David (1999). Group Dynamics, 3, 275278.

Dodge, K. A., \& Pettit, G. S. (2003). A biopsychosocial model of the development of chronic conduct problems in adolescence. Developmental Psychology, 39, 349-371.

Dubow, E. F., Huesmann, L. R., \& Boxer, P. (2003). Theoretical and methodological considerations in cross-generational research on parenting and child aggressive behavior. Journal of Abnormal Child Psychology, 31, 185-192.

Eargle, A., Guerra, N. G., \& Tolan, P. (1994). Small-group treatment for children living in high violence neighborhoods. Journal of Child and Adolescent Group Therapy, 4, 229-243.

Epstein, J. L. (1989). The selection of friends: Changes across the grades and in different school environments. In T. J. Berndt \& G. W. Ladd (Eds.), Peer Relationships in Child Development (pp. 158-187). New York: Wiley.

Eron, L. D. (1987). The development of aggressive behavior from the perspective of a developing behaviorist. American Psychologist, $42,435-442$.

Eron, L. D. (1994). Theories of aggression: From drives to cognitions. In L. R. Huesmann (Ed.), Aggressive behavior: Current perspectives (pp. 3-11). New York: Plenum.

Eron, L. D., Guerra, N. G., \& Huesmann, L. R. (1997). Poverty and violence. In S. Feshbach \& J. Zagrodzka (Eds.), Aggression: Biological, developmental, and social perspectives (pp. 139-154). New York: Plenum.

Eron, L. D., Walder, L. O., \& Lefkowitz, M. M. (1971). Learning of aggression in children. Boston: Little, Brown.

Espelage, D. L., Holt, M. K., \& Henkel, R. R. (2003). Examination of peer-group contextual effects on aggression during early adolescence. Child Development, 74, 205-220.

Farrell, A. D., Meyer, A. L., Kung, E. M., \& Sullivan, T. N. (2001). Development and evaluation of school-based prevention programs. Journal of Clinical Child Psychology, 30, 207-220.

Feindler, E. L., Marriott, S. A., \& Iwata, M. (1984). Group anger control training for junior high school delinquents. Cognitive Therapy and Research, 8, 299-311.

Feindler, E. L., \& Scalley, M. (1998). Adolescent anger management groups for violence reduction. In K. C. Stoiber (Ed.), Handbook of group intervention for children and families (pp. 100-119). Needham Heights, MA: Allyn \& Bacon.

Flanagan, K. S., Bierman, K. L., Kam, C., \& the Conduct Problems Prevention Research Group. (2003). Identifying at-risk children at school entry: The usefulness of multibehavioral problem profiles. Journal of Clinical Child and Adolescent Psychology, 32, 396407.

Goldstein, N. E., Arnold, D. A., Rosenberg, J. L., Stowe, R. M., \& Ortiz, C. (2001). Contagion of aggression in day care classrooms as a function of peer and teacher responses. Journal of Educational Psychology, 93, 708-719.

Gordon, R. (1983). An operational definition of prevention. Public Health Reports, 98, 107-109.

Granic, I., \& Dishion, T. J. (2003). Deviant talk in adolescent friendships: A step toward measuring a pathogenic attractor process. Social Development, 12, 314-334.

Guerra, N. G., Eron, L. D., Huesmann, L. R., Tolan, P. H., \& Van Acker, R. (1997). A cognitive-ecological approach to the prevention and mitigation of violence and aggression in inner-city youth. In P. Fry \& K. Bjorkqvist (Eds.), Cultural variation in conflict resolution: alternatives for reducing violence (pp. 199-213). New York: Polonium.

Guerra, N. G., \& Huesmann, L. R. (2004). A cognitive-ecological model of aggression. International Review of Social Psychology, 17, 177203.

Guerra, N. G., Huesmann, L. R., \& Spindler, A. (2003). Community violence exposure, social cognition, and aggression among urban elementary-school children. Child Development, 74, 15611576 
Guerra, N. G., Huesmann, L. R., Tolan, P. H., Van Acker, R., \& Eron, L. D. (1995). Stressful events and individual beliefs as correlates of economic disadvantage and aggression among urban children. Journal of Consulting and Clinical Psychology, 63, 518-528.

Hektner, J. M., August, G. J., \& Realmuto, G. M. (2003). Effects of pairing aggressive and nonaggressive children in strategic peer affiliation. Journal of Abnormal Child Psychology, 31, 399-412.

Henry, D., Guerra, N., Huesmann, L. R., Tolan, P., Van Acker, R., \& Eron, L. D. (2000). Normative influences on aggression in urban elementary school classrooms. American Journal of Community Psychology, 28, 59-81.

Howard, K. A., Flora, J., \& Griffin, M. (1999). Violence-prevention programs in schools: State of the science and implications for future research. Applied and Preventive Psychology, 8, 197-215.

Hudley, C., Britsch, B., Wakefield, W. D., Smith, T., Demorat, M., \& Cho, S. (1998). An attribution retraining program to reduce aggression in elementary school students. Psychology in the Schools, 35, 271282.

Hudley, C., \& Graham, S. (1993). An attributional intervention to reduce peer-directed aggression among African-American boys. Child Development, 64, 124-138.

Huesmann, L. R. (1988). An information processing model for the development of aggression. Aggressive Behavior, 14, 13-24.

Huesmann, L. R. (Ed.). (1994). Aggressive behavior: Current perspectives. New York: Plenum.

Huesmann, L. R. (1998). The role of social information processing and cognitive schema in the acquisition and maintenance of habitual aggressive behavior. In R. G. Geen \& E. Donnerstein (Eds.), Human aggression: Theories, research, and implications for social policy (pp. 73-109). San Diego, CA: Academic Press.

Huesmann, L. R., \& Moise, J. (1998). The stability and continuity of aggression from early childhood to young adulthood. In D. J. Flannery, \& C. R. Huff (Eds.), Youth Violence: Prevention, Intervention, and Social Policy (pp. 73-95). Washington, DC: American Psychiatric Press.

Huesmann, L. R., Eron, L. D., \& Dubow, E. F. (2002). Childhood predictors of adult criminality: Are all risk factors reflected in childhood aggressiveness? Criminal Behaviour and Mental Health, 12, 185208.

Huesmann, L. R., Eron, L. D., Guerra, N. G., \& Crawshaw, V. B. (1994). Measuring children's aggression with teachers' predictions of peer nominations. Psychological Assessment, 6, 329-336.

Huesmann, L. R., Eron, L. D., \& Yarmel, P. W. (1987). Intellectual functioning and aggression. Journal of Personality and Social Psychology, 52, 232-240.

Human Capital Initiative. (1996). Reducing violence: A research agenda. Washington, DC: American Psychological Association.

Kerns, S. E. U., \& Prinz, R. J. (2002). Critical issues in the prevention of violence-related behavior in youth. Clinical Child and Family Psychology Review, 5, 133-160.

Kiesner, J., Poulin, F., \& Nicotra, E. (2003). Peer relations across contexts: Individual-network homophily and network inclusion in and after school. Child Development, 74, 1328-1343.

Larson, J., \& Lochman, J. E. (2002). Helping schoolchildren cope with anger: A cognitive-behavioral intervention. New York: Guilford.

Leventhal, T., \& Brooks-Gunn, J. (2003). Children and youth in neighborhood contexts. Current Directions in Psychological Science, 12, 27-31.

Little, R. J. A., \& Rubin, D. B. (1987). Statistical analysis with missing data. New York: Wiley.

Lochman, J. E., \& Lenhart, L. A. (1993). Anger coping intervention for aggressive children: Conceptual models and outcome effects. Clinical Psychology Review, 13, 785-805.
Mahoney, A., Donnelly, W. O., Boxer, P., \& Lewis, T. (2003). Marital and severe parent-to-adolescent physical aggression in clinic-referred families: Mother and adolescent reports on co-occurrence and links to child behavior problems. Journal of Family Psychology, 17, 319.

Metropolitan Area Child Study Research Group. (2002). A cognitiveecological approach to preventing aggression in urban settings: Initial outcomes for high-risk children. Journal of Consulting and Clinical Psychology, 70, 179-194.

Miles, D. R., \& Carey, G. (1997). Genetic and environmental architecture of human aggression. Journal of Personality and Social Psychology, 72, 207-217.

Murray, M. E., Guerra, N. G., \& Williams, K. R. (1997). Violence prevention for the 21 st century. In R. P. Weissberg \& T. P. Gullotta (Eds.), Healthy children 2010: Enhancing children's wellness (pp. 105-128). Thousand Oaks, CA: Sage.

Newcomb, A. F., Bukowski, W. M., \& Bagwell, C. L. (1999). Knowing the sounds: Friendship as a developmental context. In A. Collins \& B. Laursen (Eds.), Minnesota symposia on child development: Vol.30 Relationships as developmental contexts (pp. 63-84). Mahwah: Erlbaum.

Patterson, G. R., DeBaryshe, B. D., \& Ramsey, E. (1989). A developmental perspective on antisocial behavior. American Psychologist, 44, 329-335.

Patterson, G. R., Dishion, T. J., \& Yoerger, K. (2000). Adolescent growth in new forms of problem behavior: Macro- and micro-peer dynamics. Prevention Science, 1, 3-13.

Poulin, F., Dishion, T. J., \& Burraston, B. (2001). Three-year iatrogenic effects associated with aggregating high-risk adolescents in cognitive-behavioral preventive interventions. Applied Developmental Science, 5, 214-224.

Poulin, F., Dishion, T. J., \& Haas, E. (1999). The peer influence paradox: Friendship quality and deviance training within male adolescent friendships. Merrill-Palmer Quarterly, 45, 42-61.

Raudenbush, S. W., \& Bryk, A. S. (2002). Hierarchical linear models (2nd ed.). Thousand Oaks, CA: Sage.

Raudenbush, S. W., Bryk, A. S., Cheong, Y. F., \& Congdon, R. T. (2000). HLM 5: Hierarchical linear and nonlinear modeling. Lincolnwood, IL: Scientific Software International, Inc.

Reid, J. B., Patterson, G. R., \& Snyder, J. (2002). Antisocial behavior in children and adolescents: A developmental analysis and model for intervention. Washington, DC: American Psychological Association.

Spindler, A., \& Huesmann, L. R. (1999). Combining peer and teacher reports to measure children's aggressive behavior. Unpublished manuscript, University of Michigan.

Stoolmiller, M., Eddy, J. M., \& Reid, J. B. (2000). Detecting and describing preventive intervention effects in a universal school-based randomized trial targeting delinquent and violent behavior. Journal of Consulting and Clinical Psychology, 68, 296-306.

Surgeon General. (2001). Youth violence: A report of the surgeon general. Rockville, MD: U.S. Department of Health and Human Services.

Tolan, P. H., \& Guerra, N. G. (1994). Prevention of delinquency: Current status and issues. Applied and Preventive Psychology, 3, 251-273.

Tolan, P. H., Guerra, N. G., \& Kendall, P. C. (1995). A developmentalecological perspective on antisocial behavior in children and adolescents: Toward a unified risk and intervention framework. Journal of Consulting and Clinical Psychology, 63, 579-584.

Wilson, S. J., Lipsey, M. W., \& Derzon, J. H. (2003). The effects of school-based intervention programs on aggressive behavior: A meta-analysis. Journal of Consulting and Clinical Psychology, 71, 136-149. 